\title{
Bipolar Bozukluk ve Yaygın Anksiyete Bozukluğu Eş Tanılı Alkol Kullanım Bozukluğunda Naltrekson Tedavisi
}

\author{
Hilmi Ertuğ BAKİ ${ }^{1}$, Mevhibe İrem YILDIZ ${ }^{2}$, Berna Diclenur ULUĞ $\breve{~}^{3}$
}

\begin{abstract}
Özet: Bu yazıda alkol kullanım bozukluğu (AKB) bulunan, bipolar bozukluk ve yaygın anksiyete bozukluğu (YAB) eş tanıları olan olgunun naltrekson ile tedavisinin akut ve uzun dönemli etkilerinin sunulması amaçlanmıştır. Yoğun alkol kullanımı ile birlikte tetiklenen birçok mani ve depresyon atağı olan 35 yaşında erkek hastada 20 yıla yakın hastalık süresince, yaygın anksiyete belirtileri duygudurum dönemlerine eşlik etmiş. Çeşitli duygudurum dengeleyiciler ve antipsikotiklerin yanı sıra 17 yıl boyunca klonazepam(2-4 mg/gün) kullanmış. Servise yatırılarak detoksifikasyon sürecine başlandıktan sonra naltrekson $100 \mathrm{mg} / \mathrm{gün}$ başlanan hastanın taburculuk sonrasında 1 yıldır alkol kullanımı olmadı ve duygu durumu ötimik olarak izlendi. Naltreksonun bipolar bozukluğu olan hastalarda alkol kullanımını azalttığı gösterilmiştir. Bu olguda da naltrekson tedavisi ile bir yıl boyunca bipolar bozukluk ve alkol kullanım bozukluğuyla ilgili nüks olmadığ görülmüştür. Bipolar bozukluk ve YAB'de tedavi etkinliğinin artması bakımından AKB'nin tedavisinin göz ardı edilmemesi önem taşımaktadır.
\end{abstract}

Anahtar sözcükler: Naltrekson, Bipolar Bozukluk, Alkol, Bağımlılık, Anksiyete

\section{Naltrexone Treatment in Alcohol Use Disorder Comorbid With Bipolar Disorder and \\ Generalized Anxiety Disorder}

\begin{abstract}
In this article, we aimed to present the acute and long-term effects of naltrexone treatment in a patient withalcohol use disorder (AUD) comorbid with bipolar disorder and generalized anxiety disorder (GAD). In a 35-year-old man with many episodes of mania and depression induced by intense alcohol use, there has been many affective episodes with anxiety symptoms for 20 years. He has used clonazepam (2-4 mg/day) for 17 years as well as various mood stabilizers and antipsychotics. After hospitalization, naltrexone $100 \mathrm{mg} / \mathrm{day}$ was started. After the discharge he didn't use alcohol for one year and his mood was euthymic. Naltrexone has been shown to reduce alcohol use in patients with bipolar disorder. In this case, there was no recurrence of bipolar disorder and alcohol use disorder for one year with naltrexone treatment.It is important to treatment of AUD for increasing treatment efficiency in bipolar disorder and GAD.
\end{abstract}

Keywords: Naltrexone, Bipolar Disorder, Alcohol Use Disorder, Anxiety

\footnotetext{
${ }^{1}$ Araş.Gör.Dr., Üniv. Tıp Fak., Ruh Sağlığı ve Hastalıkları AD

${ }^{2}$ Dr. Öğr. Üyesi Tıp Fak., Ruh Sağlığı ve Hastalıkları AD

${ }^{3}$ Prof.Dr., Hacettepe Üniv. Tıp Fak., Ruh Sağlığı ve Hastalıkları AD

Address of correspondence/ Yazışma adresi: Araş.Gör.Dr., Hilmi Ertuğ Baki, Hacettepe Üniv. Tıp Fak., Ruh Sağlığı ve Hastalıkları AD., Ankara, E-mail: hebaki@ hacettepe.edu.tr
}

Date of Received/Geliş Tarihi: 01.10.2019, Date of Revision/Düzeltme Tarihi: 02.11.2019, Date of Acceptance/Kabul Tarihi: 06.11.2019

Citing/ Referans Gösterimi: Baki, H.E., Yıldız, M.İ. Uluğ, B.D. (2019). Naltrexone Treatment in Alcohol Use Disorder Comorbid With Bipolar Disorder and Generalized Anxiety Disorder. Kıbrıs Türk Psikiyatri ve Psikoloji Dergisi, 1(Özel Sayı.1): 66-68 doi:10.35365/ctjpp.19.special1.19 


\section{Giriş}

Alkol kullanım bozukluğu bipolar bozukluk ve yaygın anksiyete bozukluğuna sıç̧a eşlik edebilmektedir(Cardoso ve ark. 2008). Eş tanılı durumlarda alkol kullanım bozukluğunun tedavisi gözden kaçabilmekte ve bu durum eş tanıların tedavisini de zorlaştırabilmektedir(Weiss ve ark. 2009). Alkol kullanım bozukluğunun tedavisinde dünyada ve ülkemizde onaylı ilaçlar disülfiram, akamprosat, naltrekson ve nalmefendir. Naltrekson seçici olmayan opioid reseptör antagonistidir, alkol kullanım bozukluğunda depreşme oranını azaltır ve ayıklık süresini uzatır(Evren ve Bozkurt 2015). Bu yazıda alkol kullanım bozukluğu bulunan, bipolar bozukluk ve yaygın anksiyete bozukluğu eş tanıları olan olguda alkol kullanım bozukluğunun naltrekson ile tedavisinin akut ve uzun dönemli etkilerini sunmayı amaçladık.

\section{Olgu}

35 yaşında, sosyoloji bölümü mezunu, memur, erkek hasta, lise ikinci siniftayken anksiyete belirtilerini yatıştırmak amacıyla günde 4-5 bira içmeye başlamış. 2001 yılında 17 yaşındayken major depresyon tanısıyla paroksetin başlanmasından sonra diğer insanların düşüncelerini okuduğunu düşünme, günlerce uyumama, yakınlarına karşı saldırganlık gibi belirtiler ortaya çıkmış ve alkol kullanımında artış olmuş. 'Bipolar bozukluk psikotik mani' dönemi düşünülerek paroksetin kesilmiş ve ketiapin tedavisi başlanmış. Takip eden yıllarda yoğun alkol kullanımı ile tetiklenen mani ve depresyon atakları hızlı bir döngü içinde görülmeye başlamış, yaygın anksiyete belirtileri duygudurum dönemlerine eşlik etmiş.

On yedi yıllık ilaç tedavisi öyküsüne bakıldığında, hastaya çeşitli duygudurum dengeleyicilerin ve antipsikotiklerin verilmiş olduğu; bunların yan sıra çok uzun yıllar boyunca klonazepam (2-4 mg/gün) kullanmış olduğu görülmektedir. Bu tedavilere rağmen duygudurum dönemleri kontrol altına alınamayan, anksiyete belirtileri düzelmeyen, alkol ve klonazepamı birlikte kullanmaya devam eden hasta bölümümüz yataklı servisine yatırıldı. Yatışı sırasında klonazepam $2 \mathrm{mg}$ /gün, olanzapin 7,5 $\mathrm{mg} /$ gün, lamotrijin $50 \mathrm{mg} /$ gün tedavilerini kullanıyordu.

Yatışı sırasındaki ruhsal durum muayenesinde, duygudurumu hafif çökkün, duygulanımı azalmıştı. Hamilton Depresyon Derecelendirme Ölçeği (HADD) puanı 8'idi. Kötü bir şey olacakmış hissi, huzursuzluk, seslerden tedirgin olma gibi şikâyetleri vardı. Bu şikâyetlerine zaman zaman çarpıntıeşlik ediyordu. Hastanın geçmişteki tedavi öyküsüne bakıldığında, en dikkat çeken özellik, ek tanılı durumlarda çok sık rastlandığı üzere alkol kullanım bozukluğunun yirmi yıla yakın bir süredir hiç ele alınmamış olmasıydı. Alkol ve klonazepamı birlikte kullanılıyor oluşu, hastanın sürekli biçimde intoksikasyon ve kesilme/yoksunluk dönemlerine girip çıkmasına sebep oluyor; anksiyete ve duygudurum belirtileri bir yandan yatışıp bir yandan tetikleniyor ve hastalık seyri gittikçe karmaşıklaşıyor ve kötüleşiyordu.

Hastanın alkol ve benzodiazepin kullanımının yatışı öncesi güne kadar devam etmesi nedeniyle detoksifikasyon tedavisi planland. Hasta uzun süredir klonazepam kullandığını bu tedaviyi bırakmakta çok zorlanacağını söyledi. Klonazepam kesilerek lorazepam tedavisi başlandi. Lorazepam dozu kademeli olarak azaltıldı ancak doz azaltılırken titreme, bulantı ve baş ağrısı olması nedeniyle lorazepam kesilme sürecinde de Alkol Yoksunluğu Değerlendirme Ölçeği-CIWA-Ar (Clinical Institute Withdrawal Assessment for AlcoholRevised) uygulandı, yatışı sırasında 5 olan CIWA-Ar puanı izlemde en yüksek 10'a çıktı. Duygudurum dengeleyici olarak lityum başlandı, kullanmakta olduğu lamotrijin tedavisi kesildi. Hasta ile alkol ve benzodiazepin kullanımını bırakmasıyla ilgili motivasyonel görüşmeler yapıldı. Benzodiazepin ve alkol kullanma isteğini azaltması amacıyla naltrekson 100 $\mathrm{mg} /$ gün başlandı. Detoksifikasyon sürecinde kullanılan lorazepam kesildikten sonra hasta 2 hafta daha servisimizde izlendi. Yaygin anksiyete belirtilerine yönelik pregabalin $150 \mathrm{mg} /$ gün başlandı. Olanzapin kesilerek ketiapin $300 \mathrm{mg} /$ gün başlandı. Hastanın anksiyete belirtileri izlemde azaldı. Taburculuğu sırasında HADD skoru 4, CIWA-Ar skoru 0'idi. Taburculuk sonrası ilk dönemde haftada bir sonrasında 2 haftada bir olmak üzere yaklaşık 1 yıldır ayaktan takip edilen hastanın duygudurumu ötimik olarak izlendi. Birkaç kez alkol içme isteğinin olduğunu fakat alkol kullanımının olmadığını belirtti.

\section{Tartışma}

Alkol kullanım bozukluğu(AKB) olan kişilerde diğer psikiyatrik bozuklukların birlikte bulunma olasılığ genel topluma göre daha yüksektir(Di Nicola ve ark. 2017). AKB'nin bipolar bozukluk ile birlikteliği \%3846(Cardoso ve ark. 2008), yaygın anksiyete bozukluğuyla birlikteliği \%8-52 olarak tespit edilmiştir(Evren 2010). Psikiyatrik komorbidite bizim hastamızda olduğu gibi erken yaşta başlayan bipolar bozuklukta daha fazladır (Joslyn ve Hawes 2015).

Bipolar bozukluk hastaları yaşadıkları afektif belirtileri düzeltmek amacıyla ya da dürtüsel davranış eğilimleri sonucunda s1k ve yüksek miktarda alkol kullanabilmektedir(Farren ve ark. 2012). Olgumuzda da afektif dönemlerde alkol kullanımı artmaktadır. Alkol kullanım bozukluğu bulunan bipolar bozukluk hastaları duygudurum düzenleyici tedaviden daha az yarar görür, ilaç uyumları düşük olur ve bu hastalarda daha sık hastaneye yatış görülür(Weiss ve ark. 2009).

Olguya bakıldığında hastanın geçmişte alkol kullanım bozukluğuna yönelik bir tedavi kullanmamış olması dikkat çekicidir. AKB'de kullanılabilen naltreksonun tedavi sırasında yüksek düzeyde aşerme yaşayanlarda, ailede AKB öyküsü olanlarda ve ağır içiciliği olanlarda daha faydalı olduğu gösterilmiştir(Monterosso ve ark. 2001). Hastamızın da babasında AKB olması, günde 5 birimin üstünde alkol kullanması gibi özellikleri nedeniyle, naltreksonun hastanın tedavisinde yeri olabileceği düşünülmüştür. Naltreksonun bipolar bozukluğu olan hastalarda yapılan bir randomizekontrollü çalışmada alkol kullanım sıklığını ve miktarını azalttığ1 gösterilmiştir(Brown ve ark. 2006). Bu olguda da yoğun alkol ve benzodiazepin kullanımının ardından diğer tedavilere ek olarak kullanılan naltrekson ile 1 y1l boyunca bipolar bozukluk ve alkol kullanım bozukluğuyla ilgili nüks olmadığı görülmüştür.

\section{Sonuç}

$\mathrm{Bu}$ olguda 20 yıla yakın bir süre boyunca bipolar bozukluk ve yaygın anksiyete bozukluğuna eşlik eden AKB'ni tedavisi ele alınmıştır. AKB'nin etkin bir 
biçimde tedavi edilmesinin bipolar bozukluk ve yaygın anksiyete bozukluğunun da remisyon süresini uzattığ1 görülmüş̧ür. Bipolar bozuklukta sıklıkla eş tanı olarak bulunan AKB'nin tedavisinin göz ardı edilmemesi, bipolar bozukluk ve yaygın anksiyete bozukluğunda tedavi etkinliğinin artması bakımından önem taşımaktadır.

\section{Kaynaklar}

Brown, E.S., Beard, L., Dobbs, L., Rush, A.J. (2006) Naltrexone in patients with bipolardisorder and alcohol dependence Depress Anxiety. 23:492-495

Cardoso, B.M., Sant'Anna, M.K., Dias, V.V., Andreazza, A.C., Ceresér, K.M., Kapczinski, F. (2008) The impact of co-morbid alcohol use disorder in bipolar patients Alcohol 42(6): 451-457

Evren, C., Bozkurt, M. (2015) Alkol kullanım bozukluğunda farmakolojik tedavi seçenekleri, Düşünen Adam Dergisi 28: 283300

Evren, C. (2010) Sosyal anksiyete bozukluğu ve alkol kullanım bozuklukları, psikiyatride güncel yaklaşımlar, 2010; 2(4):473515

Farren, C.K., Hill, K.P., Weiss, R.D. (2012) Bipolar disorder and alcohol use disorder: a review. Curr Psychiatry Rep. 14(6):659-66
Joslyn, C., Hawes, D. (2015) Is age of onset associated with severity, prognosis, and clinical features in bipolar disorder? A meta- analytic review Bipolar Disord. 18: 389-403

Monterosso, J.R., Flannery, B.A., Pettinati, H.M., Oslin, D.W., Rukstalis, M., O'Brien, C.P., Volpicelli, J.R. (2001) Predicting treatment response to naltrexone: the influence of craving and family history. Am J Addict; 10:258-268.

Nicola, M.D., Filippis, S., Martinotti, G., Risio, L.D., Pettorruso, M., Persis, S. (2017) Nalmefene in alcohol use disorder subjects with psychiatric comorbidity: a naturalistic study. Adv Ther. 34(7):1636-1649

Weiss, R.D., Griffin, M., Jaffee, W., Bender, R.E., Graff, F.S., Gallop, R.J., Fitzmaurice, G.M. (2009) A "community-friendly" version of integrated group therapy for patients with bipolar disorder and substance dependence: a randomized controlled trial. Drug Alcohol Depend. 104(3):212-9 